\title{
A Criticality-based Approach for the Analysis of Smart Grids
}

\author{
Polinpapilinho F. Katina ${ }^{1}$ (D) . Charles B. Keating ${ }^{1} \cdot$ Enrico Zio $^{2} \cdot$ Adrian V. Gheorghe $^{1}$
}

Received: 22 February 2016 / Accepted: 30 September 2016 / Published online: 19 October 2016

(c) Springer Science+Business Media Singapore 2016

\begin{abstract}
Smart Grids offer higher level capabilities intended to meet current and future energy demands. These demands include improved performance related to concepts of reliability, resiliency, environmentally friendly generation, transmission, and distribution as well as turning consumers into prosumers. This study focused on two primary objectives: (1) to understand how the concept of risk is currently being addressed in Smart Grids, and (2) to suggest a more holistic view of risk for Smart Grids. Pertinent literature on Smart Grids was collected and synthesized for the concept of risk which indicated the prevalence of two factors, probability and consequence, as the main factors for Smart Grid risk quantification. However, it was discovered that current literature appears to focus on risk within the different domains of Smart Grids (i.e., generation, transmission, distribution, customer, service provide, operations,
\end{abstract}

Polinpapilinho F. Katina

pkatina@odu.edu

Charles B. Keating

ckeating@odu.edu

Enrico Zio

enrico.zio@polimi.it

Adrian V. Gheorghe

agheorgh@odu.edu

1 National Centers for System of Systems Engineering, Department of Engineering Management \& Systems Engineering, Old Dominion University, 2101 Engineering Systems Bld., Norfolk, VA 23529, USA

2 Energy Department, Nuclear Division, Laboratory of Signal Analysis and Risk Analysis, Politecnico di Milano, Via Ponzio 34/3 20133, Milano, Italy markets) without consideration Smart Grids as an integrated whole. A criticality-based approach (CBA) is proposed and then used as the basis for development of an extended listing of measures, including dependency, interdependency, and resiliency, as well as accepted risk factors (i.e., probability and consequence). This confluence of factors can be utilized in a holistic Smart Grid analysis. Implications for CBA and future research directions for realizing enhanced Smart Grid capabilities are provided.

Keywords Critical infrastructure $\cdot$ Criticality-based approach · Operating landscape $\cdot$ Risk formulation . Smart Grid

\section{Introduction}

There is wide recognition that modern society depends on goods and services provided by a set of complex systems typically referred to as critical infrastructures. These systems are often referred to as critical since they are essential for maintaining and sustaining public well-being, safety, and economic prosperity [26, 42, 55, 73]. The domain of critical infrastructures revolves around chemicals, commercial facilities, communications, critical manufacturing, dams, defense industrial bases, emergency services, energy, financial, services, food and agriculture, government facilities, healthcare and public health, information technology, nuclear reactors, materials, and waste water systems [67]. Lately, there is increasing interest in the energy sector with respect to the critical importance of Smart Grids as a critical infrastructure [11, 15, 54, 57, 72, 75]. Arguably, Smart Grids, similar to all critical infrastructures, operate under conditions of uncertainty with respect to natural events such as earthquakes and hurricanes as well as 
man-made events such as acts of sabotage and cyber-threats [42, 80, 86, 92]. Moreover, Smart Grids must be designed, operate, and evolve in a difficult context. This context is marked by elements of: (1) ambiguity associated with an increasing lack of clarity and situational understanding, complexity associated with large numbers of richly and dynamically interacting systems and subsystems with behavior difficult to predict, (2) emergence with respect to the inability to deduce behavior, structure, or performance from constituent elements, and (3) interdependency associated with mutual influence among different complex systems through which the state of a system influences, and is influenced by, the state of other interconnected systems $[12,51]$.

Against this backdrop, current research tends to focus on the potential benefits of Smart Grids [23] as well as issues and risks in implementation such as new cyber-threats and vulnerabilities [7, 13, 14, 36, 37]. Moreover, and perhaps due to the nascent nature of this topic, researchers are still debating the definitions of Smart Grids [21, 40, 70, 78] as well as focusing on particular aspects and parts/elements of Smart Grids, including design for next-generation control centers [91], optimizing distributed power systems [75] effects of plug-in-hybrid-electric vehicles [33], security issues [4, 6, 8, 62, 64], Smart Meters [90], standards and best practices $[32,87]$, and classification of threats $[4,15$, 54] among others. However, there is still a scarcity of literature discussing quantitative methods that could be used in support of risk quantification for Smart Grids.

The idea of risk quantification for Smart Grids is not new. Concepts of probability of occurrence of an event and its consequences have been adapted for Smart Grids [11, 32, 40, 57-59, 62, 72, 90]. However, adapting traditional risk formulation without accounting for other relevant measures is limiting in analyzing Smart Grids. Moreover, current literature could be considered atomistic since there is a tendency to focus on specific elements such as smart metering systems and integration of distributed power generation of the Smart Grid, without consideration of Smart Grids as a totality. Thus, there is a gap in the literature for developing more robust formulations of risk related to more holistic considerations for integrated Smart Grid systems. This research attempts to address this gap by exploring a robust set of measures (and their properties) that could be used for more holistic examination of Smart Grids. The purpose of this paper is to propose and develop an alternative framework that could be used to explore the 'criticality' of Smart Grids. For purposes of this research, the term criticality is related to the importance of a Smart Grid to public well-being.

The paper is organized around three primary development thrusts to support the purpose of the research. First, we describe Smart Grids in terms of the present domain and major characteristics that delineate the domain. The aim of this section is to articulate the complexities involved in developing, implementing, and evolving Smart Grids. Special emphasis is placed on the more holistic view of Smart Grids as an integrated system that includes technologies, information (availability, accessibility, utility), human and social influences, organizational and managerial supporting arrangements, and political (policy) constraints as well as facilitation considerations. Second, the concept of risk is explored. Specifically, the literature is reviewed with respect to risk and factors commonly used in current quantification efforts related to risk for Smart Grids. Third, we provide a preliminary extended set of measures that could be used in addressing criticality of Smart Grids. This set of measures and their properties is developed by contrasting current factors with previous research of criticalitybased measures. This research concludes with proposed future research directions based on the current investigation implications.

\section{Smart Grid Characteristics and Landscape}

The topic of Smart Grid is relatively new and as such there is no one widely accepted definition [40, 70]. Thus, it is necessary to explore the concept of Smart Grid to develop a foundational perspective before delving into the concept of risk for Smart Grids. At a fundamental level, a Smart Grid can be considered "an upgrade to the current electrical power grid" ([8], p. 24). Consequently, a Smart Grid is expected to meet current needs while offering significantly higher capabilities that are intended to meet ever changing societal demands of the $21^{\text {st }}$ century and beyond [54]. These social demands are highlighted by the need for reliable, resilient, scalable, manageable, and environmentally friendly energy generation, transmission, and distribution systems that also embody concepts of interoperability, cost effectiveness, and intelligence [6, 23, 31, 54]. Unfortunately, there is no one consistent perspective of what a Smart Grid entails. Table 1 is provided to illustrate the varying representative perspectives of Smart Grids.

Although, there is no one accepted perspective of Smart Grids, the selected set of perspectives begins to offer insight into essential aspects, components and characteristics of Smart Grids. A common theme of transforming the structure of electrical energy generation, delivery and consumption with an increasing emphasis on information and technology and interests of the consumer, appear to be driving the evolving paradigm of Smart Grids. The Institute of Electrical and Electronics Engineers (IEEE) definition, "integration of power, communications, and information technologies for an improved electric power infrastructure serving loads while providing for an ongoing evolution of enduse applications" ([38], p. 3), appears to capture most 
Table 1 A representative set of perspectives on smart grids

\begin{tabular}{|c|c|}
\hline Author(s) & Description of the selected perspective \\
\hline Baumeister [8], p. 1 & $\begin{array}{l}\text { an electrical power infrastructure that makes intelligent decisions about the state of the electrical } \\
\text { power system to maintain a stable environment }\end{array}$ \\
\hline McBride and McGee [62], p. 91-92 & $\begin{array}{l}\text { evolution of the power grid entails upgrading the infrastructure to a 'smart grid' to support two- } \\
\text { way communication between electric generation, transmission and distribution infrastructure, and } \\
\text { consumers of power [and involves] emerging smart grid applications such as advanced metering } \\
\text { infrastructure (AMI), synchrophasors, distribution automation (DA), automated demand response, } \\
\text { electric vehicles, and microgrid management }\end{array}$ \\
\hline Pearson [70], p. 5212 & $\begin{array}{l}\text {...a network that can intelligently integrate the actions of all user connected to it - generators, } \\
\text { consumers and those that do both - in order to efficiently deliver sustainable, economic and } \\
\text { secure electricity supplies... fusing the physical delivery network with any number of separate } \\
\text { ICT[information and communication technology]-enabled applications such as intelligent sensors, } \\
\text { software, communications, and distributed control technologies... bring[ing] a host of benefits to } \\
\text { both consumers and producers of electricity alike }\end{array}$ \\
\hline Ray et al. [72], p. 276 & $\begin{array}{l}\text {.. a paradigm shift in ways electric energy is produced, traded and consumed. Most visions of } \\
\text { modernization of the electricity generation and delivery infrastructure would involve integration of } \\
\text { diverse, connected, interdependent and adaptive functions and applications to enhance grid } \\
\text { reliability, improve capital and operational efficiency and ensure security of the electric grid.. } \\
\text { comprising of advanced sensing, control, communication and information processing, emergent } \\
\text { intelligence distributed across various segments of the power grid will transform the grid to a highly } \\
\text { interactive and adaptive system }\end{array}$ \\
\hline European Union [22], p. 45 & $\begin{array}{l}\text {...means an electricity network that can integrate in a cost efficient manner the behaviour and actions } \\
\text { of all users connected to it, including generators, consumers and those that both generate and } \\
\text { consume, in order to ensure an economically efficient and sustainable power system with low losses } \\
\text { and high levels of quality, security of supply and safety }\end{array}$ \\
\hline
\end{tabular}

perspectives. To further expound on these representative perspectives, we now turn attention to the common basic components and characteristics of Smart Grids.

Similar to differing Smart Grid perspectives, there are also different perspectives on components (elements) that constitute Smart Grids. Baumeister [8], from a cybersecurity perspective, suggests that there are five categories of major themes for Smart Grids. Table 2 presents these categories along with their typical associated elements. These themes are directly related to each being a "component of the Smart Grid" ([8], p. 6) from the security perspective of Smart Grids.

Describing Smart Grids in terms of security domain appears as a dominant theme in literature. This might be attributed to increased coupling of information in the energy sector which has created new vulnerabilities [61]. These new vulnerabilities are especially inclusive of threats of the cyber-kind [13, 78, 86, 87].

An alternative approach for describing Smart Grids is provided through the lens of architectural representations. A block diagram is provided by Balaji and Ram [6] to illustrate Smart Grid as a "vast network comprising utilities and customers who are linked by the power transmission as well as communication infrastructure. The other entities in the network are involved in providing value added services for improving efficiency and facilitation of buying and selling of power driven by supply demand dynamics" ([6], p. 2903). A hierarchical architecture model has also been suggested by Moslehi and Kumar [63]. Their approach is based on the need for "harnessing modern communication and information technologies to enable an IT [Information technology] infrastructure that provides gridwide coordinated monitoring and control capabilities" and as such, it is mainly focused on "operating concerns in categories such as performance enhancement, equipment limits, operating limits, system protection, and rapid recovery" ([63], p. 60) with an emphasis on functional tasks of the elements comprising a Smart Grid. Yet another model of a Smart Grid is suggested by Komninos et al. [54] in the form of a multi-layered conceptual model that illustrates three major sections of a Smart Grid as well as its parts and their interactions. These representations provide a means by which a typical Smart Grid can be viewed as a complex of interrelated parts and elements [10, 32]. Consequently, these views are compatible with contemporary research trends of focusing on elements, their interactions in a grid, and exchange of information [32, 62, 72].

Perhaps a more comprehensive view of the Smart Grid is provided by IEEE's Standard 2030-2011 [38]. This standard articulates major entities and functions of a Smart Grid that aligns with the National Institute of Standards and Technology [NIST] framework for Smart Grids. Figure 1 is adapted from NIST [65] to depict the seven domains of a Smart Grid. The solid blue lines indicate the secure information and communication flows. The red dotted lines represent electricity flows. 
Table 2 Baumeister's [8] categories and components of the smart grid

\begin{tabular}{|c|c|c|}
\hline Security component & Area of focus & Description \\
\hline Process control system [PCS] security & $\begin{array}{l}\text { Supervisory control and } \\
\text { data acquisition (SCADA) }\end{array}$ & $\begin{array}{l}\text { Deals with controlling and monitoring the physical aspects } \\
\text { of the electrical power grid. This aspect is essential since } \\
\text { Smart Grid elements are often geographical distributed }\end{array}$ \\
\hline Smart meter security & Smart meter & $\begin{array}{l}\text { Deals with Smart Meters which are installed into consumer } \\
\text { homes and serve as an interface between a home and the } \\
\text { energy provider for exchange of information. There is a } \\
\text { growing concern that Smart Meters could acts as access- } \\
\text { points and manipulated }\end{array}$ \\
\hline Power system state estimation security & Power system state estimation & $\begin{array}{l}\text { Deals with having the ability to control physical properties } \\
\text { of an electrical power system to maintain a stable state - } \\
\text { making informed decisions in response to changes in } \\
\text { demands }\end{array}$ \\
\hline Smart grid communication protocol security & Communication components & $\begin{array}{l}\text { Smart Grid relies on exchange of information and data } \\
\text { between different components and elements of the system } \\
\text { in order to function }\end{array}$ \\
\hline Smart grid simulation for security analysis & Models and simulations & $\begin{array}{l}\text { Power systems are expected to be operational on a conti- } \\
\text { nuous basis, testing any Smart Grid designs or changes } \\
\text { are difficult task. Instead, it is possible to develop models } \\
\text { that can be used for analysis }\end{array}$ \\
\hline
\end{tabular}

Each of the seven 'domains' can contain a number of interrelated complex systems along with logical interfaces (i.e., access points) in which information can enter/exit a domain [38, 65]. Table 3 depicts the seven domains of a Smart Grid as well as entities commonly associated with those domains. While this table does not place emphasis on the interfaces among the different domains of a Smart Grid, it forms the basis for suggesting that each domain could be viewed as a complex system. Guckenheimer

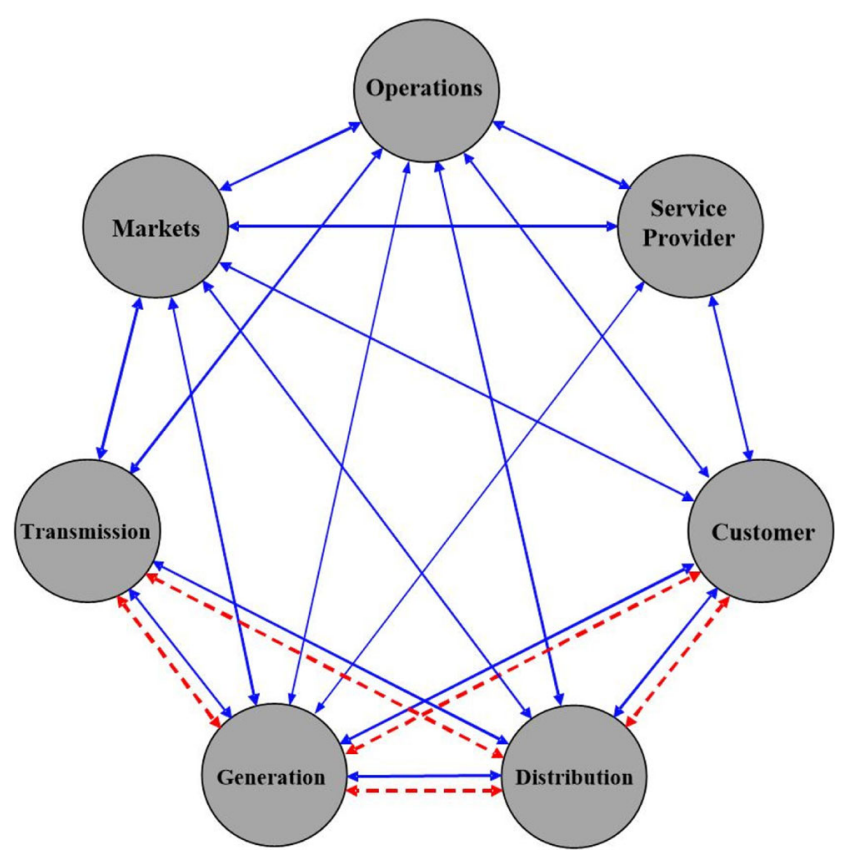

Fig. 1 A conceptual model of a smart grid and Ottino's [30] four distinctive properties of a complex system (i.e., many interacting parts, emergent behavior, adaptation and change, systems uncertainty) appear present for Smart Grids. For example, Advanced Metering Infrastructure, which is a building block for the customer domain, is described as a complex set of interrelated elements [4, 17, 62].

Arguably, when it comes to describing Smart Grids, none of these perspectives are incorrect. In fact, these perspectives are all necessary to set the basis for developing best practices for designing, maintaining, and realizing the premises of Smart Grids [32, 70, 84]. In fact, the perspectives also serve as the basis for creating measures and indicators that are instrumental in assessing performance of Smart Grids [78]. Inevitably, these perspectives can be used to enhance our understanding of the logic of various domains and their interrelations in Smart Grids [62]. Beyond the different articulations of Smart Grids, and perhaps more importantly, is the fact that there appears to be a set common themes that describe general 'characteristics' of Smart Grids [6, 14, 63, 68, 78]. Table 4 provides a set of common set of 'characteristics' of Smart Grids that are drawn from pertinent literature.

The discussion regarding components and the unifying 'characteristics' of Smart Grids were purposefully selected to illustrate three important points. First, the topic of Smart Grid is still in its infancy and therefore should be expected to be loosely bounded and harbor a degree of diverging and sometimes conflicting perspectives. Having diverging perspectives is not troubling. Rather, as [48] suggest, different perspectives put forward "show the potential sources of divergence in the development of the [Smart 


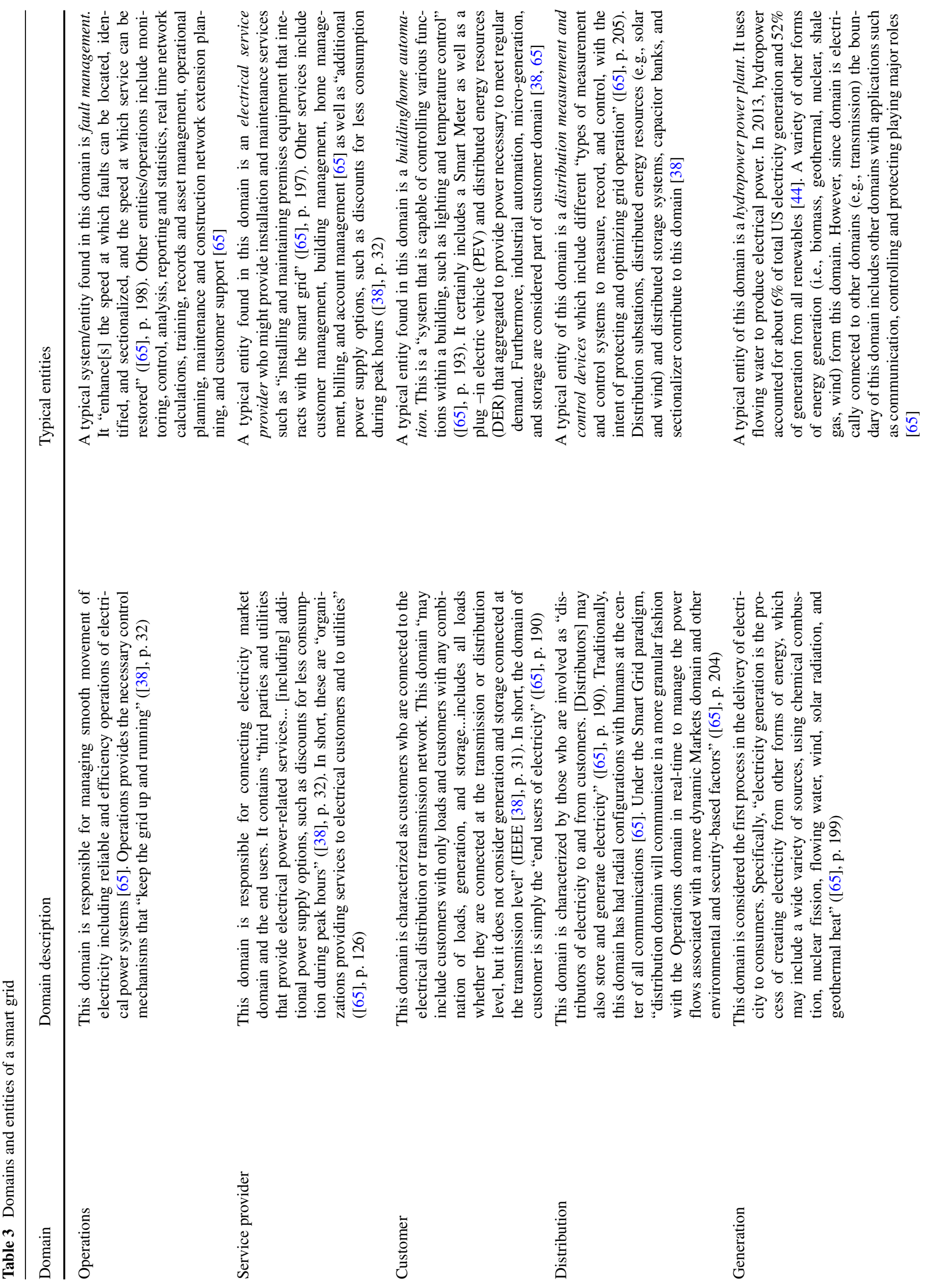




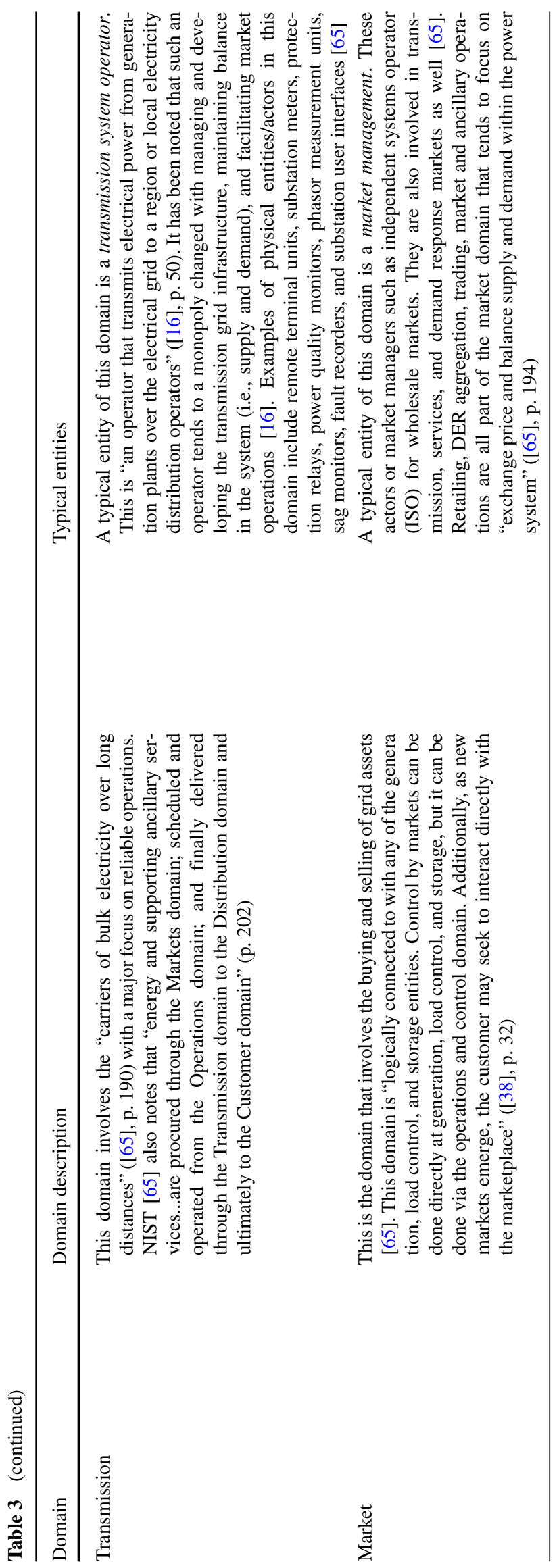

Grid] field...[with] Each perspective brings[ing] a logic which provides its own internal validation to the community which produces and consumes the perspective" ([48], p. 240). Second, the field of Smart Grids can be identified as existing within the domain of critical infrastructure which "addresses elements of assessment, remediation, indications and warnings, mitigation, response, and reconstruction pertaining to hazards, risks, and threats from natural and manmade events affecting public well-being, public safety, economic vitality, and security" ([25], p. 194). Increasing concerns about frequency of occurrence of risk events, such as breaches, as well as their potential effects on public wellbeing, highlights the relative importance of Smart Grids as it relates to public well-being, including considerations of health, security, and economic impact [11, 47, 62, 90]. Third, the operating landscape/environment for Smart Grids is characteristically complex, involving a range of socio and technical issues [92]. The articulation of the current state of the Smart Grids problem domain can be characterized consistent with earlier works [45, 46, 48-51] and the notion of 'messes' by [1] as well as 'wicked problems' by [74]. Table 5 provide articulates characteristics of a landscape from which Smart Grids are projected to operate. This operating landscape suggests a need for robust analysis methods in all aspects of realization of Smart Grids.

One key aspect of realization of Smart Grids is risk. There is a growing support suggesting the need to address 'risk' related to Smart Grids [11, 15, 32, 33, 40, 54, 57, 62, $72,75,90,91]$. The following section provides an initial exploration into the concept of risk for Smart Grids as well as its quantification.

\section{The Concept of Risk in Smart Grids}

There is no one widely accepted definition of the term 'risk.' However, risk is typically defined in terms of probability of occurrence of an event and the magnitude of the resulting consequences [5, 24]. The vast literature on this topic also suggests that elements of event sequence and probabilities [71], technical factors in a system life cycle [39], probabilities of unknown outcomes and uncertainties [28], uncertainty [35, 53], perception of risk [88], mental constructs of risk [26], and 'unknown unknowns' [69] are also essential considerations related to risk quantification. Most recently, the concept of interdependency is increasingly incorporated into risk quantification [47, 73, 79]. Regardless of subtle and wide ranging distinctions related to the risk, a general consensus is that occurrence of a risk event can cause undesirable effects related to such issues as cost, schedule, and or technical performance of a system [18].

There is no shortage of risk events that can affect performance of Smart Grids. These range from natural events such 
Table 4 Unifying characteristics of smart grids

\begin{tabular}{lcc}
\hline Smart Grid characteristic & Description & Supporting Sources \\
\hline $\begin{array}{c}\text { Three indispensable factors for Smart } \\
\text { Grid reliability are availability, }\end{array}$ & There are evident of the importance of security measures & {$[4,8,17,19,20,38,40$,} \\
for Smart Grids [4, 62]. At the same time, Baumeister & $65,66,72,82,86,90]$
\end{tabular}

confidentiality, and integrity

Enabling informed participation by customers

Accommodating all generation and storage options

Enabling new products, services and markets

Provides the power quality for the range of needs [8] notes that countermeasuring procedures against threats should "not impede power availability or safety" ([8], p. 4). In addressing security issues, three objectives of availability, confidentiality, and integrity have taken precedence:

- Availability - is described as "the most important security objective" ([8], p. 4) which involves "ensuring timely and reliable access to and use of information is of the most importance in the Smart Grid" ([86], p. 1348). Loss of availability is in itself a disruption since it prevents access and use of information which can further undermine electricity delivery

- Confidentiality - "Preserving authorized restrictions on information access and disclosure is mainly to protect personal privacy and proprietary information. This is in particular necessary to prevent unauthorized disclosure of information that is not open to the public and individuals" ([86], p. 1348)

- Integrity - "Guarding against improper information modification or destruction is to ensure information nonrepudiation and authenticity. A loss of integrity is the unauthorized modification or destruction of information and can further induce incorrect decision regarding power management" ([86], p. 1348)

Consumers help balance supply and demand, and ensure reliability by modifying the way they use and purchase electricity. Under the paradigm of Smart Grid, a consumer evolves into 'prosumer' who not only consumes electricity but produces and stores electricity [29]. This is meant to enable prosumers to have choices that motivate different purchasing patterns and behaviours related to electricity usage and influencing pricing as well as incentives [68]

A smart grid accommodates not only large, centralised power plants, but also the growing array of customer-sited distributed energy resources. Integration of these resources - including renewables, small-scale combined heat and power, and energy storage - will increase rapidly all along the value chain, from suppliers to marketers to customers ([68], p. 7)

The paradigm of Smart Grid enables efficient market operations that enable the prosumers to choose among competing services. Some of the independent grid variables that must be explicitly managed are energy, capacity, location, time, rate of change and quality. Markets will play a major role in the management of these variables. Regulators, owners/operators and consumers need the flexibility to modify the rules of business to suit operating and market conditions [68]

Not all commercial enterprises, and certainly not all residential customers, need the same quality of power. A smart grid supplies varying grades (and prices) of power. The cost of premium power-quality features can be included in the electrical service contract. Advanced control methods monitor essential components, enabling rapid diagnosis and solutions to events that impact power quality, such as lightning, switching surges, line faults and harmonic sources ([68], p. 7)
$[14,63,68,78]$

$[14,38,63,65,68,78]$

$[14,38,63,65,68,78]$

$[14,38,63,65,68,78]$ 
Table 4 (continued)

Smart Grid characteristic

Optimises asset utilisation and operating efficiency

Providing resiliency to disturbances, attacks and natural disasters

Enabling two-way communications model

Smart grid deployment enables significant $\mathrm{CO}_{2}$ emissions reductions
Description

A smart grid applies the latest technologies to optimise the use of its assets. For example, optimised capacity can be attainable with dynamic ratings, which allow assets to be used at greater loads by continuously sensing and rating their capacities. Maintenance efficiency can be optimised with condition-based maintenance, which signals the need for equipment maintenance at precisely the right time. System-control devices can be adjusted to reduce losses and eliminate congestion. Operating efficiency increases when selecting the least-cost energy-delivery system available through these types of system-control devices ([68], p. 7)

Resiliency has been defined as "the ability to withstand, recover from, and reorganize in response to crises" ([60], p.7) and includes elements of "defensive characteristics (e.g., deterrence, detection, delay, response, time to recovery; system defensive properties (e.g., physical barriers), maintenance capability to resist attacks; susceptibility, adaptive capacity, time to repair, availability of warning systems, and critical time" ([25], p. 195). Smart Grids are expected to be resilient to all hazards [78] as well have having the self-healing capability to reduce interruption of electricity delivery to prosumers [68]

A Smart Grid opens up the means for prosumers and utility to interact. Traditionally, meters provided reading for a total consumption of electricity over a given period of time. However, a Smart Grid, especially the introduction of an advanced metering infrastructure (AMI), introduces a number of technologies, in addition Smart Meters that enable two-way flow of information including real-time pricing and consumption. AMI functionalities include, among others, remote consumer price signals, which can provide time-of-use pricing information [68]

Although electricity consumption only represents $17 \%$ of final energy use today, it leads to $40 \%$ of global $\mathrm{CO}_{2}$ emissions, largely because almost $70 \%$ of electricity is produced from fossil fuel...Taking these direct and indirect emissions reductions into account, the ETP BLUE Map Scenario estimates that Smart Grids offer the potential to achieve net annual emissions reductions of 0.7 Gt to $2.1 \mathrm{Gt}$ of $\mathrm{CO}_{2}$ by 2050 ([68], p. 27). The increased awareness of effects of emissions as well is advanced technologies provide the industry an incentive to develop Smart Grids [6]
Supporting Sources

$[14,38,63,65,68,78]$

$[14,38,63,65,68,78]$

$[14,38,54,63,65,68,68,78]$

$[2,6,14,17,68]$ as extreme weather conditions [57, 75] to man-made acts such as cyber-threats $[4,21]$. The increasing frequency of such events coupled with their potential negative effects on public well-being suggests a need for development of riskrelated approaches that could be used in understanding such emerging risks as well as aid in decision-making processes to mitigate their impact and/or prevent their occurrence altogether. However, we contend that current literature related to risk in relationship to Smart Grids suffers from two primary deficiencies: (1) it accounts for a limited set of traditional factors for quantification of risk and (2) it is atomistic in analysis for Smart Grids since it focuses on specific domains and elements of Smart Grids (e.g. transmission). These issues form the basis for remainder of this article as well as development of an extended set of measures that could be used in a more systemic analysis to aid in understanding and designing Smart Grids.

First, it is essential to recognize that the traditional risk formulation has been adapted for application to Smart Grids. For example, [59] suggests that an overload risk 
Table 5 The operating landscape for smart grids and implications

\begin{tabular}{ll}
\hline Characteristic & Description \\
\hline Proliferation of information & $\begin{array}{c}\text { The information explosion has created unparal- } \\
\text { leled levels of quantity and access to information }\end{array}$
\end{tabular}

Smart grid problem domain implications

leled levels of quantity and access to information

Conflicting perspectives and divergence in stakeholder views

Scarce and dynamically shifting resources

Unintended consequences

Ambiguous boundaries

Politically charged positions

Solution urgency

Unclear entry point or approach
Given the abundance of information and varying degrees of interpretation, conflicts in perspectives concerning situations, and the appropriate path forward for their resolution, are inevitable

Resources have always been scarce and constrained. However, the short view and demands for immediate response to emergent issues creates a climate of instability in assurance of continuing resource availability

High degrees of uncertainty and incomplete knowledge exacerbate the occurrence of behaviours and patterns that were not intended or anticipated

Boundaries are essential to determine what is included and excluded in a complex system. They can be arbitrary, permeable, and dynamically shifting

Politically charged environments for complex systems are marked by attempts to pursue strategies to influence decisions, actions, and interpretations

There has always been an urgency to resolve issues related to complex system problems. However, current environments are increasing demands for instant gratification and resolution of system problems

The degree of complexity for modern systems and their resulting problems occur on a continuous basis. There is no prescription or clear point of entry or exit to address related issues
Rapid technological changes and the quantity of information on Smart Grids could make it difficult to filter information resulting in poorly informed decisions, and lack of appropriate/timely information straining decision processes [89]

Without adequate means to identify, explore, and resolve the underlying sources of diverging perspectives in Smart Grids, decisions, actions, and interpretations of Smart Grids is left to the inherent inefficiencies created by disparities in underlying worldviews such that ideas about the system are not be the same for all interested and disinterested parties [9]

In a traditional form of planning, there is an assumption regarding stability in the environments. However, it is increasingly evident that there is uncertainty regarding availability and performance of Smart Grids due to security related issues [78], intermittency in distributed energy resources [75], and a lack of knowledge base [65]. These instabilities create a potential for a dramatic shift in resource availability and capability

There has always been a desire to precisely understand direct cause-effect relationships [3, 70]. For Smart Grids this degree of prediction, understanding, or control is not attainable, forcing robust designs to deal with emerging patterns of behaviours

There is a large degree of ambiguity as to the boundary of Smart Grids. This issue is more evident in attempts to generate a general criterion for definition of a Smart Grid. The boundary of what is included/exclude appears to shift based on the topic of research

Politics exist in all complex systems involving humans. Politics are neither good nor bad. However, politics and policy must be accounted for in the development, design, analysis, and execution of Smart Grid, not ignored. Certainly, this involves the means to obtain rights-of-way to build long-distance transmission lanes crossing local and national boundaries [92]

Increasing urgency for solutions causes premature tradeoffs of time for other essential aspects of Smart Grid problem domain understanding and evolution. Premature conclusions of analysis are likely to result in superficial treatment of symptomatic, incomplete solutions, and unresolved deep system issues [41, 49]

Left without a clear entry point, the inevitable result is that each entry point for Smart Grid will offer both advantages and disadvantages. These may change over time as shifts occur in the context as well as understanding of Smart Grid operating landscape 
assessment for a transmission line can be drawn from probability overload at a given line and the severity of the overload on the system. Rocchetta et al. [75] have also developed a simulation-based risk-cost optimization framework that accounts for high wind, solar irradiation, and lightning as major issues affecting failure rates in the overhead distribution lines of Smart Grids. The summation of probability of undesired events and the severity of the related consequences are used as the primary factors for risk articulation related to Smart Grids. Corresponding contingency frequencies related to unexpected loss of one or more elements (e.g. distribution line, transformer, etc.) and overload are used for risk estimation. Specifically, Rocchetta et al. [75] used a Monte Carlo simulation approach with a continuous Weibull distribution to illustrate the importance of integrating distributed power systems into a Smart Grid environment to counter the effects of extreme weather on availability of electricity. These approaches are similar to those of [40] and [91] with both using traditional factors of probability and consequence, although in different context, architecture of a Smart Grid for the former and Smart Control Center for the later.

Undoubtedly, electric, hybrid electric, and plug-in hybrid electric vehicles present a desirable potential for substantial impact on pollution, climate change, and energy utilization. However, and as indicated by Hashemi-Dezaki et al. [33], increased and especially unmanaged charging of these vehicles "may adversely [the] affect electric distribution system" ([33], p. 262). Hashemi-Dezaki and his colleagues
[33] suggest that implementing managed charging with a schedule for charging plug-in hybrid electric vehicles is beneficial as it does not compromise the reliability of a Smart Grid. Similar to [75], Hashemi-Dezaki et al. [33] also uses a Monte Carlo simulation. However, risk is directly tied to reliability measures of mean time to failure (MTTF) and mean time to repair (MTTR). These examples point to the need for holistic consideration of Smart Grids to better capture unintended consequences which may accrue as the system operates.

Beyond measures articulated above, literature also indicates a unique set of factors that could be used in association with analysis of Smart Grids. For example, [62] suggests that risk analysis for a utility system could involve the goal of the adversary (i.e., motivation for attacking a business), threat agent availability, potential threat vectors, exposure, target attractiveness, and impact of attack. These measures, according to [62] are instrumental in identification of vulnerability, prioritization of the threats, and development of countermeasures. Table 6 is a summary of literature depicting risk-related measures in different areas of Smart Grids.

This section was developed to illustrate how risk is currently being addressed in the Smart Grid literature as well as the implications for further development. Authors draw two primary conclusions based on this literature. First, it is evident that contemporary literature focuses on risk separately in the specific domains and elements associated with Smart Grids. This would then suggest that approaches for

Table 6 A synthesis of literature positioning in different aspects of risk for smart grids

\begin{tabular}{|c|c|c|c|}
\hline Author(s) & $\begin{array}{l}\text { Traditional factors (i.e., probability } \\
\text { and consequence) }\end{array}$ & Area of application & Additional unique set of factors \\
\hline [11] & Yes & A defined focus of interest & Vulnerability; Potential attack paths \\
\hline$[15,32]$ & Yes & Smart Grid (Whole) & $\begin{array}{l}\text { Probable effectiveness of security } \\
\text { measures; Lack of security } \\
\text { measures }\end{array}$ \\
\hline$[33]$ & Yes & Charging of plug-in hybrid electric vehicles & Reliability \\
\hline [40] & Yes & Smart Grid Architecture & - \\
\hline [59] & Yes & Transmission line overload & - \\
\hline$[57]$ & Yes & Smart Grid Architecture & Risk index system for Smart Grids \\
\hline$[62]$ & Yes & Risk from a security perspective & $\begin{array}{l}\text { Availability of threat agents; } \\
\text { Potential treat vectors; Expo- } \\
\text { sure; Attractiveness of the } \\
\text { target; Ease of attack }\end{array}$ \\
\hline$[72]$ & Yes & Smart Grid security & $\begin{array}{l}\text { Effectiveness of countermea- } \\
\text { sures; Vulnerability; Tolerance } \\
\text { of stakeholders }\end{array}$ \\
\hline$[75]$ & Yes & Distributed power generation systems & $\begin{array}{l}\text { Total number of lines in the } \\
\text { system; Total number of nodes }\end{array}$ \\
\hline [90] & Yes & Smart Meter & Vulnerability \\
\hline [91] & Yes & Smart control center & - \\
\hline
\end{tabular}


risk quantification would necessarily be expected to vary from domain to domain within Smart Grids. For example, the approach for transmission lines [59] significantly varies from a security-related approach [62]. It might be reasonably expected to have different approaches in the different domains of Smart Grids since certain factors are domain-specific. However, this focus on risks related to the constituent domains offers limited utility to those who might be involved at an integrated level of Smart Grids, which exist beyond individual domains. At the higher (systems) level of Smart Grids, risks cannot be assumed to be aggregates of mutually exclusive and independent risks of the constituent domain risks. Thus, risks at the Smart Grid exist at a different logical level than those of the constituent domains and cannot be simple inferred from domain level risks. An analysis based on simple extrapolation of constituent domain risks are tenuous at best and outright wrong at worst. If the objective is to analyze Smart Grids at a system level, we must look beyond simple aggregation of risks from constituent domains. Second, traditional risk formulation of probability and consequence is prevalent across the literature and in the individual constituent domains for
Smart Grids and offers a good starting point to rethinking analysis of the higher logical (systemic) level for Smart Grids. More advanced, and arguable more appropriate, risk literature also points to consideration of a more robust set of factors that might be useful quantifying risk for Smart Grids (e.g. dependency, interdependency, resilience). It is from this perspective that we propose developing an extended set of factors that could be used in more holistic analysis of Smart Grids.

\section{Holistic Risk Formulation for Smart Grids}

The need for holistic approaches to risk analysis for Smart Grids is not new [32, 40]. It has long been recognized that the evolving nature of threats coupled with the ' $\mathrm{E}+\mathrm{I}$ ' (i.e., energy and information) paradigm [26] have transformed the thinking from the traditionally isolated systems perspective into a more "highly interconnected and interdependent system of local and wide area information and communication systems" ([72], p. 276) perspective. This means consideration of interactions and interdependencies

Table 7 A set of factors for smart grid risk quantification

\begin{tabular}{|c|c|c|}
\hline Author(s) & Unique set of factors & Operational description \\
\hline [62], p. 98 & Attractiveness of the target [F1] & $\begin{array}{l}\text { How motivated an attacker would be to compromise the target - which can be related } \\
\text { to the potential reward, the geopolitical or military significance of the target, the } \\
\text { value of the information and the general public's interest in information on the } \\
\text { target (including privacy-related aspects) }\end{array}$ \\
\hline [62], p. 98 & Availability of threat agents [F2] & $\begin{array}{l}\text { Availability of threat agents - agents including "company employees, terrorists, } \\
\text { espionage agents, extortionists, hackers, cyber-criminals, customers, and outsour- } \\
\text { ced maintenance staff" that are willing to realize a threat" }\end{array}$ \\
\hline$[11,62]$ & Availability of attack routes [F3] & $\begin{array}{l}\text { Presence of routes/paths that can be used to exploit a system a Smart Grid and } \\
\text { involves such mediums as wireless access points, intranet, mobile devices (e.g., } \\
\text { USB devices) and Smart Meters }\end{array}$ \\
\hline$[15,32,62,72]$ & Ineffective protection measures [F4] & $\begin{array}{l}\text { Exploitability of a system which relates to how easy a Smart Grid can be attacked } \\
\text { because of lack of security measure or having ineffective security measures such } \\
\text { that "probability of [an] interception [of a threat] and the probability of neutralizing } \\
\text { a given threat" ([32], p. 4) is low }\end{array}$ \\
\hline [62] & Exposure [F5] & $\begin{array}{l}\text { Entails a "condition of being unprotected from a severe condition" ([47], p. 15) and } \\
\text { involves being 'exposed to' threats }\end{array}$ \\
\hline [33] & Reliability [F6] & $\begin{array}{l}\text { The probability that a system will perform its intended mission(s) when called } \\
\text { upon to do so [47]. In a Smart Grid, reliability is related to being available "in } \\
\text { the widespread presence of PHEVs [plug-in-hybrid-electric vehicles]" ([33], } \\
\text { p. 263) }\end{array}$ \\
\hline [72] & Tolerance of stakeholders [F7] & $\begin{array}{l}\text { The willingness to allow existence of some risks and/or behavior that one does not } \\
\text { necessarily agree with }\end{array}$ \\
\hline [75] & Total number of lines [F8] & $\begin{array}{l}\text { The number of lines (e.g., power lines, communication nodes, etc.) used in trans- } \\
\text { mitting electricity and information from one point to another }\end{array}$ \\
\hline [75] & Total number of nodes [F9] & $\begin{array}{l}\text { The number of points on a transmission line where two or more transmission lines } \\
\text { meet }\end{array}$ \\
\hline [90] & Vulnerability [F10] & $\begin{array}{l}\text { A feature of a system that represents a susceptibility to a threat. A vulnerability may, } \\
\text { be a weakness, flaw or deficiency, or it may be an intentional aspect of the system" } \\
\text { ([90], p. 88) }\end{array}$ \\
\hline
\end{tabular}


among different domains of Smart Grids (i.e., generation, transmissions, distribution, customers, markets, operations, and service providers) as well as the other systems in the environment [40]. Under this emerging paradigm, Ray and his colleagues suggest the development of a unified risk model that considers "interconnections of domains...variety of dynamic and structural interactions" for Smart Grids ([72], p. 281). In light of these insights, there is an increased call to rethink how risk is formulated [42, 43, 47] with respect to the complexities that are endemic to modern systems and higher level domains such as Smart Grids.

In this section, we develop an extended list of factors that can be used for analysis of Smart Grids. Although it is not presented as the definitive listing of factors, it is offered as a first articulation for moving beyond the narrower conceptions of risks in Smart Grids. As such, the factors can, should, and will evolve with further development, insights, and applications. As a first step in this exploration, we examine a set of extended factors identified from the Smart Grid literature. A review of existing factors suggests that a total 10 factors from the literature (i.e., attractiveness of a target, availability of threat agents, availability of attack routes, ineffective protection measures, exposure, reliability, tolerance of stakeholders, total number of lines, total number of nodes, and vulnerability). These factors are in additional to the two traditional factors of probability and consequence that are used in different riskrelated approaches for Smart Grids. Many of these factors are terms or phrases that have an exact or nearly the same meaning used in different contexts - that is they are synonyms. For example, Bologna et al. ([11], p. 6) refers to "potential attack paths" to suggest a route that could be used to attack a system. On the other hand, McBride and McGee ([62], p. 97) use the words "potential threat vectors" to suggest potential 'channels' such the "Internet, wireless access points, the enterprise intranet, mobile devices (including USB devices), remote endpoints (including meters), the supply chain, and the company's own systems development organization" that could be used in attacking a system. Clearly, the different phrases address congruent issues and are referring to availability of routes/paths that can be used to exploit a system - in this case, a Smart Grid. The same logic is used to combine concepts of ease of attack, effectiveness of countermeasures, and lack of security measures. Table 7 summarizes a synthesis of similar terms into seemingly unique factors that can be applied at the level of Smart Grids for risk quantification.

Arguably, Katina and Hester [42] have developed a comprehensive set of factors that can be used to determine 'criticality' of infrastructure systems [85]. To this end, we can
Fig. 2 Areas of a criticality-based approach




Table 8 Mapping contemporary Smart Grid risk-related factors into criticality-based model for infrastructure systems

Criticality-based measures $\quad$ Properties for each factor $\quad$ Smart Grids risk factors $\quad$ Implications for Smart Grid research

Dependency

(1)

Interdependency
Economic importance

Effects

Criticality

Community awareness

Importance

Satisfaction

Critical quality

Scope

Impact on system users

Political relevancy

Cost to repair

External relationships

Critical proportion

Interconnectedness

F8; F9
An economic importance of a Smart Grid through dependency lens. More value would be assigned to those good and services of a Smart Grids appearing to support public well-being in economic terms

A level of effects brought through dependencies (internal or external) that could enable or disable a Smart Grid and subsequently affecting public well-being

A value of a Smart Grid and/or its components in relation to meeting pre-determined public well-being goals

Amount of work that has historically been done to mitigate hazards to Smart Grids. Intense activity could indicate extent to which stakeholders grasp level of dependency

Extent of urgency or necessity of doing work to address a threat [56]. These effects could be driven by the fact that an attacker sees a Smart Grid or its components as an 'attractive' target

Degree to which public needs and expectations are derived from performance of a Smart Grid. This could also entail acceptance of level at which Smart Grid stakeholders are working to prepare for, respond to, or mitigate potential hazards

Extent to which reduction in the quality of the expected service of a Smart Grid can be reduced before it begins to affect public well-being

Breadth and reach products and services of a Smart Grid or its component on public well-being

Magnitude and impact of a failure that could affect public well-being as a result of dependency on goods and services of a Smart Grid. A high magnitude corresponds to high dependency

Degree to which local, state, and federal authorities depend on goods and services of a Smart Grid

Cost associated with restoring a Smart Grid or its component

Number of external relationships to a Smart Grid. These relationships (i.e., links) could expose a Smart Grid to threats originating from interdependent systems

Percentage/proportion of entities and/or people that are intrinsically interconnected to a Smart Grid. The performance of a Smart Grid would be affected by increased number of interdependencies. However, this relationship would be in form of an inverse proportion such that a single relationship is what is enable/disables a Smart Grid

Level of intricate relationships within a Smart Grid. This includes relationships among the domains, components, and parts of a Smart Grid that attribute to structural complexity

Decentralization

Dispersion of a Smart Grid as a system and its parts. There might be more systems interdependent connected to a highly decentralized Smart Grid 
Table 8 (continued)

\begin{tabular}{|c|c|c|c|}
\hline Criticality-based measures & Properties for each factor & Smart Grids risk factors & Implications for Smart Grid research \\
\hline & Location & - & $\begin{array}{l}\text { Locality of a Smart Grid. A Smart Grid is likely to } \\
\text { be located in an area where is can have most posi- } \\
\text { tive impact on the users. This increases the num- } \\
\text { ber of interconnections }\end{array}$ \\
\hline \multirow[t]{10}{*}{ Resiliency } & System protective characteristics & - & $\begin{array}{l}\text { Number of a variety of mechanisms intended } \\
\text { to pre-emptively boost protection measures of a } \\
\text { Smart Grid }\end{array}$ \\
\hline & System defensive properties & F4; F6 & $\begin{array}{l}\text { Taking a reactive model of approach to Smart Grid } \\
\text { threats. This could be done through implementa- } \\
\text { tion of a number of measures that could be used } \\
\text { to resist attacks on a Smart Grid }\end{array}$ \\
\hline & Maintenance capability & - & $\begin{array}{l}\text { Availability of capability to preserve or improve } \\
\text { the state of Smart Grid operability despite } \\
\text { attempts distort it }\end{array}$ \\
\hline & Deterrence & - & $\begin{array}{l}\text { Availability of means to discourage an attack on a } \\
\text { Smart Grid in order to keep its operability status }\end{array}$ \\
\hline & Detection & - & $\begin{array}{l}\text { Ability to identify presence of concealed threats } \\
\text { that could affect Smart Grid operability }\end{array}$ \\
\hline & Delay & - & $\begin{array}{l}\text { Ability to impede an attacker from penetrating into } \\
\text { a Smart Grid, physically or otherwise }\end{array}$ \\
\hline & Adaptability & F7 & $\begin{array}{l}\text { Ability to respond and recovery from a threat as } \\
\text { soon as possible which is related time to repair } \\
\text { and well as willingness to tolerate inoperability } \\
\text { status of a Smart Grid }\end{array}$ \\
\hline & Susceptibility & - & $\begin{array}{l}\text { A state of being likely to be influenced and/or } \\
\text { harmed by extraneous agents including severe } \\
\text { weather conditions and new policy }\end{array}$ \\
\hline & Capacity & - & $\begin{array}{l}\text { Having a long-term capacity to deal with a variety } \\
\text { of sudden changes and threats while learning } \\
\text { from such changes to evolve into a more resilient } \\
\text { Smart Grid }\end{array}$ \\
\hline & Availability of warning systems & - & $\begin{array}{l}\text { Apart from having ability to detect and delay } \\
\text { threats, a well-designed Smart Grids need to have } \\
\text { capability to alert of future intrusions [52] }\end{array}$ \\
\hline \multirow[t]{6}{*}{ Risk } & Safety & - & $\begin{array}{l}\text { Ability to address concerns of being unprotected } \\
\text { from causes of danger, risk, or injury to public } \\
\text { well-being }\end{array}$ \\
\hline & Environmental factors & - & $\begin{array}{l}\text { A consideration of elements in the environment } \\
\text { [77] which exert a degree of control over the } \\
\text { processes and behavior of a Smart Grid }\end{array}$ \\
\hline & Vulnerability $^{1}$ & F10 & $\begin{array}{l}\text { A consideration of multi-dimensionality of disas- } \\
\text { ters including environmental, technical, human } \\
\text { which if exposed to a Smart Grid will damage its } \\
\text { goods and services }\end{array}$ \\
\hline & Probability of event & $\mathrm{P} 1$ & $\begin{array}{l}\text { A consideration of the likelihood that a risk event } \\
\text { will occur to halt operations of a Smart Grid. } \\
\text { The operating landscape for Smart Grids appears } \\
\text { to suggest a higher likelihood of occurrence of } \\
\text { risk events }\end{array}$ \\
\hline & Consequences & $\mathrm{C} 1$ & $\begin{array}{l}\text { Accounting for the ramifications of occurrence of } \\
\text { risk events on operability of a Smart Grid as well } \\
\text { as public well-being }\end{array}$ \\
\hline & Exclusivity & - & $\begin{array}{l}\text { Designing a Smart Grid easily accessible to every- } \\
\text { one. Total access is provided to a select number } \\
\text { of people. Inclusiveness could contribute system } \\
\text { threats }\end{array}$ \\
\hline
\end{tabular}


Table 8 (continued)

\begin{tabular}{llll}
\hline Criticality-based measures & Properties for each factor & Smart Grids risk factors & \begin{tabular}{l} 
Implications for Smart Grid research \\
\hline Intent
\end{tabular} \\
Frequency & F2 & $\begin{array}{l}\text { Accounting for availability of agents, including } \\
\text { but not limited to rogue nations and their machi- } \\
\text { nations, who have the will and intent to attack a } \\
\text { Smart Grid }\end{array}$ \\
& & $\begin{array}{l}\text { Accounting for the rate at which attacks on a } \\
\text { Smart Grid or its domains are repeated over a } \\
\text { particular period of time. Frequency of occur- } \\
\text { rence is not equivalent to occurrence of a risk } \\
\text { event. However, increasing rate could suggest a } \\
\text { greater change of failure occurrence }\end{array}$ \\
\hline
\end{tabular}

\footnotetext{
${ }^{1}$ Vulnerability has also been described as a 'state of a system' and defined as a 'threat, a predictive quantity reflecting system's selective stress reaction toward a respective threat' [83]. Authors suggests that this view may be essential when it comes to development of criticality-based models that could be used for quantification of different measures as suggested in this research. However, current research efforts are predicated upon establishing different measures (factors) that ought to be considered in the analysis of Smart Grids
}

compare contemporary Smart Grid risk factors to criticalitybased factors to develop a comprehensive set of factors to support analysis of Smart Grids. Katina and Hester [42], researchers with the National Centers for System of Systems Engineering, in their attempt to create a generalizable and transportable method for prioritizing critical infrastructures, postulated that current methodologies are sector-specific approaches and/or based on regional factors. They proposed a four-tuple of 'criticality' factors of levels of resiliency, level of interdependency, level of dependency along with infrastructure risk ${ }^{1}$ as fundamental to ranking and prioritization of infrastructures regardless of sector or region. The term 'criticality' in this sense relates to the importance of an infrastructure (e.g., a Smart Grid) to public well-being. Each of the four factors of criticality are associated with a set of properties that could be used for measuring each factor and contributes to a set of higher level criticality measures for a system. Figure 2 is drawn to capture the essence of Katina and Hester's [42] four-tuple criticality-based measures.

A mapping of the 10 seemingly unique factors from the Smart Grid literature into the criticality-based measures reveals a number of issues. First, several factors from the Smart Grid literature can be merged into single factors of the criticality-based approach. For example, total number of lines [F8] and total number of nodes [F9] are essentially addressing the effects of having a great number of interconnected systems. Nodes represent systems and lines represent the means by which such systems are

\footnotetext{
1 There are different configurations of risk assessment approaches (e.g., see $[34,81]$ ). However, the key appears to be in the consistency of the logic in which the assessment for risk could be done. In this research risk is taken as one of the elements that must be assessed in the analysis of a Smart Grid.
}

interconnected. Failure in such a system, from a criticalitybased analysis approach, is described in terms of number lines that fail after an attack, which in turn affects nodes in a Smart Grid. This issue is addressed in the interdependency criticality-factor since it includes interconnectedness of a system [42]. F4 is also combinable with F6 inasmuch as F6 is not possible if a system has ineffective protection measures. Table 8 provides a mapping of contemporary risk factors for Smart Grid risk (synthesized from literature) to those proposed by [42].

Second, there is a gap in how risk for Smart Grids is addressed. As indicated in Table 8, there are a number of properties that could be associated with one another. For example, 'community awareness' is associated to 'measure of dependency', 'external relationship' is associated to 'measure of interdependency', 'system protective' characteristics is associated to 'resiliency' and 'environmental factors' associated to 'risk.' These properties, in addition to probability and consequence, can be used to inform a more robust and holistic analysis for Smart Grids. While these properties are not presented as exhaustive, they offer a more extensive set of 'metrics' for a deeper and more rigorous analysis of Smart Grids.

Finally, applying traditional measures of probability and consequence to a specific domain of a Smart Grid offers only a partial view of the landscape within which Smart Grids operate. Subsequently, there is a need to consider the interrelationships among the seven different domains of Smart Grids. Arguably, these relationships could be explored in terms of dependency, where functioning of a given domain (e.g., distribution) is dependent on another domain (e.g., transmission). The interdependency measure recognizes that each domain (e.g., customer) influences and is also influenced by the remainder of the domains of a Smart Grid. The resiliency measure initiates the discussion 
Fig. 3 Criticality measures for Smart Grid and their representation in a radar diagram

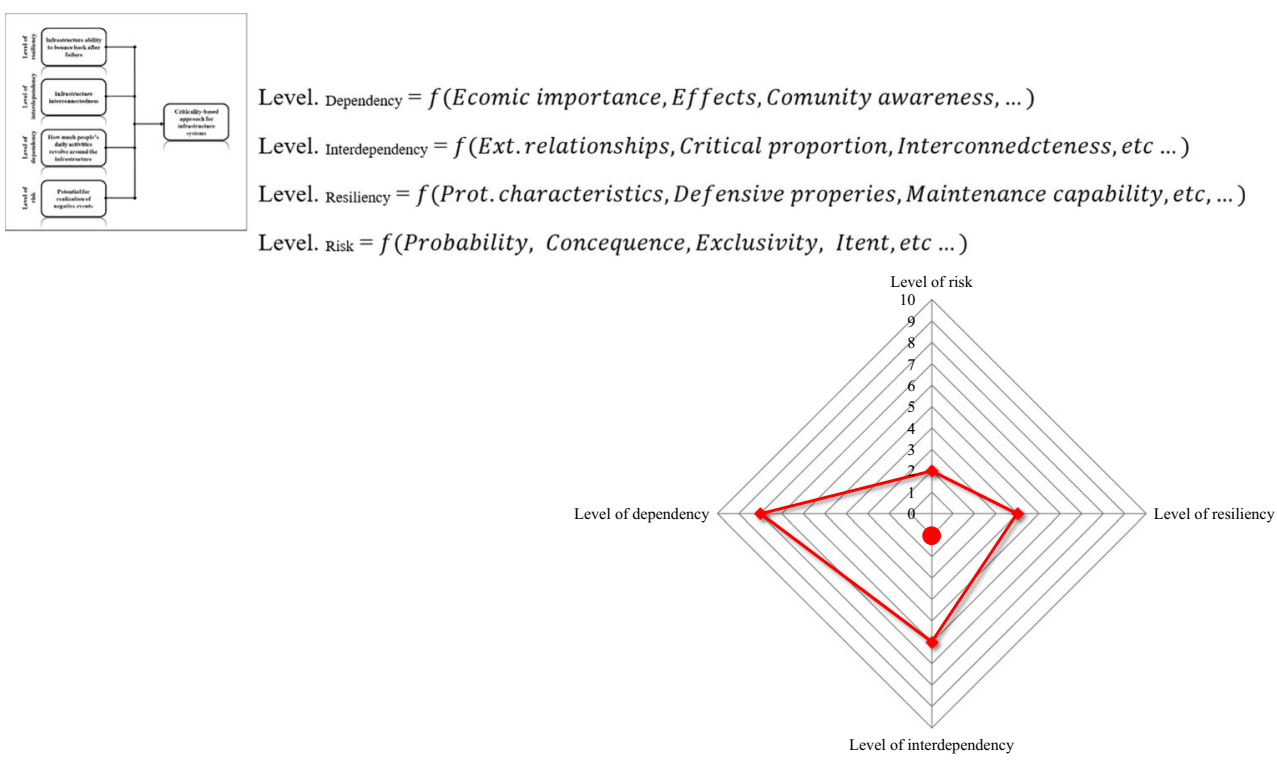

about designing Smart Grids that can withstand or rapidly recover from threats and hazards. These measures are in addition to the traditional considerations of probability and consequence associated with risk. Together, the four measures of the criticality-based approach (CBA) for analysis of Smart Grids account for several properties that could be instrumental in design, development, and analysis of Smart Grids. An operand for the proposed approach is provided as:

$$
\begin{aligned}
C r_{\text {SmartGrid }}= & f\left(\text { Level }_{\text {Dependency }} \text { Level }_{\text {Interdependency }}\right. \\
& \left.\ominus \text { Level }_{\text {Resiliency }} \ominus \text { Level }_{\text {Risk }}\right)
\end{aligned}
$$

Each level of measure, which for simplicity might range 0 to 10 , could be assessed based on the proposed properties as suggested below to offer information and insights on the state of a Smart Grid. The combination of these measures could then be used in a radar chart for the analysis of a Smart Grid as indicated in Fig. 3. Each spoke of the radar chart represents one of the four measures. In Fig. 3, the observation of a 2 for a measure of risk suggests a low risk level in a given scenario.

The proposed four-tuple measures certainly contribute to current research in different ways. At the framework level, current instantiations of risk-based frameworks have a "set of optimal steps [phases] that can be used identify, evaluate and control risk to mitigate potential negative effects in Smart Grid[s]" ([90], p. 89). Typically, these phases include risk identification, risk characterization, risk evaluation, risk mitigation planning, risk management, risk communication, and monitoring and review process at the conclusion. The proposed approach complements risk-based frameworks for Smart Grids in identifying potential issues that could affect performance as well as areas that could be in need of attention. For example, the properties associated with dependence such economic importance could enable the analyst to consider where the provision of goods and services of a Smart Grid are economically feasible. In the consideration of economic feasibility, the analyst might deliberate the role of malicious, technical, and/or natural hazards affecting the system. Therefore, this research offers a different lens through which policy-makers, Smart Grid owners, and operators might analyze Smart Grids beyond the traditional perspective of risk limited to probability and consequence. Also, observations of the different levels (continuous or incremental) of the properties might offer insights into the state of the Smart Grid such that indicators supporting more robust changes could be detected and examined.

\section{Conclusions and Future Directions}

Smart Grids, to meet the challenges and satisfy the needs of the context from which they are derived, will fundamentally be required to address a variety of issues present in their current operating landscape. Arguably, the operating landscape for Smart Grids requires that we rethink how to address risk to truly realize the full potential and contributions sought for Smart Grids. A strict view of risk that considers only probability of occurrence of an event that could halt Smart Grid operations and consequences of such an event on public well-being, offers limited utility for application to the complex nature of Smart Grids. Such a limited approach is likely to produce an overly narrow and shortterm view of risk for practitioners who must contend with a spectrum of issues that could affect performance of Smart Grids. This paper proposes an approach: criticality-based 
approach (CBA), for the analysis of Smart Grids with four measures: dependency, interdependency, resiliency, and risk (inclusive of traditional probability of occurrence and consequences). Each category measurement involves a set of properties that could be used in design, analysis, and evolution of Smart Grids as well as the development of countermeasures for issues associated with performance of Smart Grids.

While a CBA for analysis of Smart Grids is a necessary step in a robust analysis, much research remains for realization and operationalizing this approach. A primary area for development remains how to measure the different properties that contribute to the different measures associated to CBA centered on dependency, interdependency, resiliency, and risk. A starting point should certainly involve on a review of how the elements of the four-tuple are currently measured. For example, a measure of interdependency has been proposed in literature $[47,76]$. These could be adapted for Smart Grid research as well as linguistic measures (i.e., low, medium, and high) which could then be translated into numerical values [15, 27, 72]. This becomes a starting point for applications and quantification of the proposed approach for analyzing Smart Grids. Two major contributions would be: (1) the ability to compare and contrast the states of different Smart Grids and impacts of improvement initiatives and (2) establishing a baseline against which the development and improvement of a Smart Grid could be more rigorously measured.

A Smart Grid is part of the energy sector and thus related to critical infrastructures enabling production of goods and services essential for public well-being. Public well-being is intrinsically tied to measures of the CBA in Smart Grids analysis. However, there are no known well-articulated indicators or tools for measuring public well-being in relationship to Smart Grids. In response to this gap, such indicators could be developed and explicitly attributed to goods and services provided as a result of Smart Grids. This might provide a basis for relating each of the measures of the proposed approach, as well as their properties, to public well-being. This 'measurable' relationship could then form the basis for more informed decisions-making concerning allocation of scarce resources, prioritization of Smart Grid development, exploration of potential scenarios, and establishment of the level of tolerance for different issues affecting Smart Grids. In accordance with the latest reports (see [10]), such tools have to be developed and 'lab tested' to ensure operability in the real world.

Acknowledgment The researchers acknowledge funding from the Department of Engineering Management and Systems Engineering at Old Dominion University (Norfolk, Virginia, USA) and the Energy Department - Nuclear Division, Laboratory of Signal Analysis and Risk Analysis at Politecnico di Milano, (Milano, Italy).

\section{References}

1. Ackoff RL (1974) Systems, messes, and interactive planning. In: Redesigning the future: systems approach to societal problems. Wiley, New York, pp 20-33

2. Aillerie Y, Kayal S, Mennella J-P, Samani R, Sauty S, Schmitt L (2013) Smart grid cyber security: smart grid deployment requires a new end-to-end security approach (White paper). Santa Clara, CA, Intel. Retrieved from http://www.mcafee.com/tw/resources/ white-papers/wp-smart-grid-cyber-security.pdf

3. Aldeen M, Saha S, Alpcan T, Evans RJ (2015) New online voltage stability margins and risk assessment for multi-bus smart power grids. Int J Control 88(7):1338-1352. doi:10.1080/00207179.2015.1012557

4. Amin SM, Giacomoni AM (2012) Smart Grid - Safe, secure, selfhealing. IEEE Power Energ Mag 10(1):33-40

5. ASCE (2009) Guiding principles for the nation's critical infrastructure. American Society of Civil Engineers, Reston

6. Balaji AJ, Ram DSH (2015) FPGA based system for denial of service detection in smart grid. J Eng Appl Sci 10(7):29032906

7. Battaglini A, Lilliestam J, Bals C, Haas A (2008) The SuperSmart Grid. In: European Climate Forum. Postdam Institute for Climate Impact Research, Potsdam

8. Baumeister T (2010) Literature review on Smart Grid cyber security, p 34. University of Hawaii, Honolulu. Retrieved from http:// csdl.ics.hawaii.edu/techreports/10-11/10-11.pdf

9. Becker HS (ed) (1966) Social problems: a modern approach. Wiley, New York

10. Blanco MP, Prettico G, Andreadou N, Guardiola MO, Fulli G, Covrig CF (2015) Smart grids laboratories inventory 2015 (JRC Science and Policy Report No. EUR 27155 EN). Joint Research Centre, Luxembourg

11. Bologna S, Khurana H, Precsenyi Z, Rambi J, Banayoti H, Eckmaier R (2012) Assessment methodology for relevant assets: expert Group on the security and resilience of communication networks and information systems for Smart Grids (Work Package 1.4 No. DRAFT 0.9). Commission of the European Communities, Brussels, $p 9$

12. Calida BY, Katina PF (2012) Regional industries as critical infrastructures: a tale of two modern cities. Int J Crit Infrastruct 8(1):7490. doi:10.1504/IJCIS.2012.046555

13. Choo K-KR (2011) The cyber threat landscape: challenges and future research directions. Comput Secur 30(8):719-731. doi:10.1016/j.cose.2011.08.004

14. Clastres C (2011) Smart grids: another step towards competition, energy security and climate change objectives. Energy Policy 39(9):5399-5408

15. Clements SL, Kirkham H, Elizondo M, Lu S (2011) Protecting the smart grid: a risk based approach

16. Covrig CF, Ardelean M, Vasiljevska J, Mengolini A, Fulli G, Amoiralis E, Jimenez MS, Filiou C (2014) Smart Grid projects outlook 2014. Publications Office of the European Union, Petten

17. CSU - Sacramento (2012) Smart Grid cyber security potential threats, vulnerabilities and risks (No. CEC5002012047). California Energy Commission, Sacramento, p 83. Retrieved from http://www.energy.ca.gov/2012publications/CEC-500-2012-047/ CEC-500-2012-047.pdf

18. de Weck OL, Roos D, Magee CL (2011) Engineering systems: meeting human needs in a complex technological world. MIT Press, Cambridge

19. ENISA (2012) Appropriate security measures for smart grids Guidelines to assess the sophistication of security measures implementation [2012-12-06]. European Network and Information Security Agency, Heraklion, p 84 
20. ENISA (2013) Smart Grid threat landscape and good practice guide. Agency for Network and Information Security, Heraklion, pp 1-83

21. Ericsson GN (2010) Cyber security and power system communication - essential parts of a smart grid infrastructure. IEEE Trans Power Delivery 25(3):1501-1507

22. European Union (2013) Regulation (EU) No 347/2013 of the European Parliament and of the Council of 17 April 2013 on guidelines for trans-European energy infrastructure and repealing Decision No 1364/2006/EC and amending regulations (EC) N. 713/2009, (EC) No 714/2009 and (EC) No 715/2009. Off $\mathbf{J}$ Eur Union L 115:39-75. Retrieved from http://eur-lex.europa.eu/ legal-content/EN/TXT/?uri\$=\$celex\%3A32013R0347

23. Fazio M, Puliafito A, Villari M (2014) IoT4S: a new architecture to exploit sensing capabilities in smart cities. Int J Web Grid Serv 10(2/3):114-138

24. Garvey PR, Pinto CA (2009) Introduction to functional dependency network analysis. In: The 2 nd international symposium on engineering systems. Massachusetts Institute of Technology, p 17. Retrieved from http://esd.mit.edu/symp09/day3.html

25. Gheorghe AV, Katina PF (2014) Editorial: resiliency and engineering systems - research trends and challenges. Int $\mathrm{J}$ Crit Infrastruct 10(3/4):193-199

26. Gheorghe AV, Masera M, Weijnen MPC, De Vries JL (eds) (2006) Critical infrastructures at risk: securing the European electric power system, vol 9. Springer, Dordrecht

27. Gheorghe AV, Vamanu DV (2004) Towards QVA - quantitative vulnerability assessment: a generic practical model. J Risk Res 7(6):613-628. doi:10.1080/1366987042000192219

28. Gibson JE, Scherer WT, Gibson WF (2007) How to do systems analysis. Wiley-Interscience, Hoboken

29. Grijalva S, Tariq MU (2011) Prosumer-based smart grid architecture enables a flat, sustainable electricity industry. In: Innovative Smart Grid Technologies (ISGT), 2011 IEEE PES, pp 1-6

30. Guckenheimer J, Ottino JM (2008) Foundations for complex systems research in the physical sciences and engineering, Northwestern University: National Science Foundation, Evanston. Retrieved from http://www.math.cornell.edu/ gucken/PDF/nsf_ complex_systems.pdf

31. Guérard G., Amor SB, Bui A (2012) Survey on Smart Grid modelling. Int J Syst Control Commun 4(4):262-279

32. Habash RWY, Groza V, Krewski D, Paoli G (2013) A risk assessment framework for the smart grid, pp 1-6. Presented at the 2013 IEEE Electrical Power Energy Conference (EPEC), Halifax, NS, Canada. doi:10.1109/EPEC.2013.6802930

33. Hashemi-Dezaki H, Hamzeh M, Askarian-Abyaneh H, HaeriKhiavi H (2015) Risk management of Smart Grids based on managed charging of PHEVs and vehicle-to-grid strategy using Monte Carlo simulation. Energy Convers Manag 100:262276

34. Hill KN (2012) Risk quadruplet: integrating assessments of threat, vulnerability, consequence, and perception for homeland security and homeland defense (Ph.D.) Old Dominion University, United States - Virginia

35. Holton GA (2004) Defining risk. Financ Anal J 60(6):19-25

36. Hossain E, Kabalci E, Bayindir R, Perez R (2014) Microgrid testbeds around the world: state of art. Energy Convers Manag 86:132-153. doi:10.1016/j.enconman.2014.05.012

37. Hou H, Zhou J, Zhang Y, He X (2011) A brief analysis on differences of risk assessment between Smart Grid and traditional power grid (pp. 188-191). Presented at the 2011 4th international symposium on knowledge acquisition and modeling (KAM). Sanya doi:10.1109/KAM.2011.57

38. IEEE (2011) IEEE guide for smart grid interoperability of energy technology and information technology operation with the electric power system (EPS), end-use applications, and loads. IEEE Std 2030-2011, pp 1-126. doi:10.1109/IEEESTD.2011.6018239

39. INCOSE (2011) Systems engineering handbook: a guide for system life cycle processes and activities. (H. Cecilia, Ed.) (3.2 ed.). INCOSE, San Diego

40. Kammerstetter M, Langer L, Skopik F, Kupzog F, Kastner W (2014) Practical risk assessment using a cumulative Smart Grid model. In: SMARTGREENS2014. Barcelona, pp 31-42. doi: $10.5220 / 0004860900310042$

41. Katina PF (2015) Emerging systems theory-based pathologies for governance of complex systems. Int J Syst Syst Eng 6(1/2):144159. doi:10.1504/IJSSE.2015.068806

42. Katina PF, Hester PT (2013) Systemic determination of infrastructure criticality. Int J Crit Infrastruct 9(3):211-225

43. Katina PF, Pinto CA (2012) On critical infrastructure interdependency. In: The 33rd international annual conference of american society for engineering management. Curran Associates, Inc, Virginia Beach, p 10

44. Katina PF, Unal R (2015) Application of fuzzy sets in decision analysis for prioritising critical energy infrastructures. Int J Decis Sci Risk Manag 6(1):1-15. doi:10.1504/IJDSRM.2015.072762

45. Katina PF, Despotou G, Calida BY, Kholodkov T, Keating CB (2014a) Sustainability of systems of systems. Int J Syst Syst Eng 5(2):93-113. doi:10.1504/IJSSE.2014.064833

46. Katina PF, Keating CB, Jaradat RM (2014b) System requirements engineering in complex situations. Requir Eng 19(1):4562

47. Katina PF, Pinto CA, Bradley JM, Hester PT (2014c) Interdependency-induced risk with applications to healthcare. Int J Crit Infrastruct Prot 7(1):12-26. doi:10.1016/j.ijcip.2014.01.005

48. Keating CB, Katina PF (2011) Systems of systems engineering: prospects and challenges for the emerging field. Int J Syst Syst Eng 2(2/3):234-256. doi:10.1504/IJSSE.2011.040556

49. Keating CB, Katina PF (2012) Prevalence of pathologies in systems of systems. Int J Syst Syst Eng 3(3/4):243-267. doi:10.1504/IJSSE.2012.052688

50. Keating CB, Katina PF (2015) Editorial: foundational perspectives for the emerging complex system governance field. Int J Syst Syst Eng 6(1/2):1-14

51. Keating CB, Katina PF, Bradley JM (2014) Complex system governance: concept, challenges, and emerging research. Int J Syst Syst Eng 5(3):263-288

52. Klump R, Kwiatkowski M (2010) Distributed IP watchlist generation for intrusion detection in the electrical smart grid. In: Moore $\mathrm{T}$, Shenoi $\mathrm{S}$ (eds) Critical infrastructure protection, vol 4. Springer Berlin Heidelberg, New York

53. Knight FH (1921) Risk, uncertainty, and profit. Hart, Schaffner \& Marx; Houghton Mifflin Co, Boston

54. Komninos N, Philippou E, Pitsillides A (2014) Survey in smart grid and smart home security: issues, challenges and countermeasures. IEEE Commun Surv Tutorials 16(4):1933-1954

55. Kröger W, Zio E (2011) Vulnerable systems. Springer-Verlag, London

56. Li H, Apostolakis GE, Gifun J, VanSchalkwyk W, Leite S, Barber D (2009) Ranking the risks from multiple hazards in a small community. Risk Anal 29(3):438-456

57. Liu R (2013) Preliminary analysis of Smart Grid risk index system and evaluation methods. Energy Power Eng 5:807-810. doi:10.4236/epe.2013.54B155

58. Li W (2014) Risk assessment of power systems: models, methods, and applications. Wiley

59. Li X, Zhang X, Wu L, Lu P, Zhang S (2015) Transmission line overload risk assessment for power systems with wind and loadpower generation correlation. IEEE Trans Smart Grid 6(3):12331242. doi:10.1109/TSG.2014.2387281 
60. Martin-Breen P, Anderies JM (2011) Resilience: a literature review. The Rockefeller Foundation, New York, p 64. Retrieved from http://www.rockefellerfoundation.org/blog/ resilience-literature-review

61. Masera M, Stefanini A, Dondossola G (2006) The security information and communication systems and the E+I paradigm. In: Gheorghe AV, Masera M, Weijnen MPC, De Vries JL (eds) Critical infrastructures at risk: securing the european electric power system. Springer, Dordrecht, pp 85-116

62. McBride AJ, McGee AR (2012) Assessing Smart Grid security. Bell Labs Tech J 17(3):87-103. doi:10.1002/bltj.21560

63. Moslehi K, Kumar R (2010) A reliability perspective of the Smart Grid. IEEE Trans Smart Grid 1(1):57-64. doi:10.1109/TSG.2010.2046346

64. Myagmar S, Campbell R, Winslett M (2008) Security challenges of reconfigurable devices in the power grid. In: Goetz E, Shenoi (eds) Critical infrastructure protection. Springer Berlin Heidelberg, Boston, pp 147-160

65. NIST (2014) NIST framework and roadmap for smart grid interoperability standards, release 3.0 (No. NIST Special Publication 1108r3). National Institute of Standards and Technology, Gaithersburg, p 246. Retrieved from doi:10.6028/NIST.SP.1108r3

66. NISTIR (2014) Guidelines for smart grid cybersecurity: Volume 1: smart grid cybersecurity strategy, architecture, and highlevel requirements, Volume 2: privacy and the smart grid, Volume 3: Supportive analyses and references (No. NISTIR 7628, Revision 1 (3 Volumes)). National Institute of Standards and Technology, Gaithersburg, pp 1-668. Retrieved from doi:10.6028/NIST.IR.7628r1

67. Obama BH (2013) Critical infrastructure security and resilience. The White House, Washington. Retrieved from http://www.fas. org/irp/offdocs/ppd/ppd-21.pdf

68. OECD-IEA (2011) Smart grids: technology roadmap. International Energy Agency, Paris

69. Parsons VS (2007) Searching for "Unknown Unknowns". Eng Manag J 19(1):43-46. doi:10.1080/10429247.2007.11431721

70. Pearson ILG (2011) Smart Grid cyber security for Europe. Energy Policy 39(9):5211-5218

71. Price JWH (1998) Simplified risk assessment. Eng Manag J 10(1):19-23

72. Ray PD, Harnoor R, Hentea M (2010) Smart power grid security: a unified risk management approach. In: 2010 IEEE international carnahan conference on security technology (ICCST), pp 276285. doi:10.1109/CCST.2010.5678681

73. Rinaldi SM, Peerenboom JP, Kelly TK (2001) Identifying, understanding, and analyzing critical infrastructure interdependencies. IEEE Control Syst 21(6):11-25

74. Rittel HWJ, Webber MM (1973) Dilemmas in a general theory of planning. Policy Sci 4(2):155-169

75. Rocchetta R, Li YF, Zio E (2015) Risk assessment and risk-cost optimization of distributed power generation systems considering extreme weather conditions. Reliab Eng Syst Saf 136:47-61. doi:10.1016/j.ress.2014.11.013

76. Setola R (2010) How to measure the degree of interdependencies among critical infrastructures. Int J Syst Syst Eng 2(1):3859

77. Skyttner L (2005) General systems theory: problems, perspectives, practice, 2nd edn. World Scientific Publishing Co. Pte. Ltd, Singapore

78. Sun Q, Ge X, Liu L, Xu X, Zhang Y, Niu R, Zeng Y (2011) Review of Smart Grid comprehensive assessment systems. Energy Procedia 12:219-229

79. Theoharidou M, Kotzanikolaou P, Gritzalis D (2011) Risk assessment methodology for interdependent critical infrastructures. Int J Risk Assess Manag 15(2/3):128-148
80. Thissen WA, Herder PM (2003) Critical Infrastructures: state of the art in research and application. Kluwer Academic Publishers, Boston

81. Tokgoz BE (2012) Probabilistic resilience quantification and visualization building performance to hurricane wind speeds (Ph.D.) Old Dominion University, United States - Virginia

82. Tritschler M, Mackay W (2011) UK Smart Grid cyber security. Energy Networks Association, London, pp 1-81

83. Vamanu BI, Gheorghe AV, Katina PF (2016) Critical infrastructures: risk and vulnerability assessment in transportation of dangerous goods, vol 31. Springer International Publishing, Cham

84. van Opstal D (2012) Supply chain solutions for smart grid security: building on business best practices. U.S. Resilience Project, Great Falls, pp 1-36. Retrieved from https://www. controlsystemsroadmap.net/ieRoadmap\%20Documents/ SupplyChain-Solutions-for-Smart-Grid-Security.pdf

85. Vugrin ED, Turnquist MA, Brown NJK (2014) Optimal recovery sequencing for enhanced resilience and service restoration in transportation networks. Int J Crit Infrastruct 10(3-4):218246

86. Wang W, Lu Z (2013) Cyber security in the smart grid: survey and challenges. Comput Netw 57(5):1344-1371

87. Wang Y, Ruan D, Gu D, Gao J, Liu D, Xu J, Chen F, Dai F, Yang J (2011) Analysis of Smart Grid security standards. Presented at the 2011 IEEE International Conference on Computer Science and Automation Engineering (CSAE), pp 697-701. Shanghai doi:10.1109/CSAE.2011.5952941

88. Weiss JW, Anderson D (2003) CIOs and IT professionals as change agents, risk and stakeholder managers: a field study. In: Proceedings of the 36th annual Hawaii international conference on system sciences, 2003. doi:10.1109/HICSS.2003. 1174639

89. Xenias D, Axon CJ, Whitmarsh L, Connor PM, Balta-Ozkan N, Spence A (2015) UK smart grid development: an expert assessment of the benefits, pitfalls and functions. Renew Energy 81:89102

90. Yesudas R, Clarke R (2013) A framework for risk analysis in smart grid: perspective based approach. In: Luiijf E, Hartel P (eds) Critical information infrastructures security. Springer International Publishing, Cham, pp 84-95

91. Zhang P, Li F, Bhatt N (2010) Next-generation monitoring, analysis, and control for the future smart control center. IEEE Trans Smart Grid 1(2):186-192

92. Zio E, Aven T (2011) Uncertainties in Smart Grids behavior and modeling: What are the risks and vulnerabilities? How to analyze them? Energy Policy 39(10):6308-6320

Polinpapilinho F. Katina serves as a Postdoctoral Researcher with the National Centers for System of Systems Engineering and is an Adjunct Assistant Professor with the Department of Engineering and Systems Engineering at Old Dominion University (ODU), Norfolk, Virginia. He holds a PhD in Engineering Management and Systems Engineering from ODU. He has research interests in complex system governance, critical infrastructures, and system of systems engineering. He has authored more than 40 peer-reviewed papers to international conferences and journals including, International Journal of Critical Infrastructure Protection, International Journal of Critical Infrastructures, International Journal of System of Systems Engineering, and Requirements Engineering. He is a co-editor of a critical textbook on "Infranomics: Sustainability, Engineering Design and Governance." His most recent book, "Critical Infrastructures: Risk and Vulnerability Assessment in Transportation of Dangerous Goods" is in press. 
Charles B. Keating serves as Professor of Engineering Management and Systems Engineering and Director for the National Centers for System of Systems Engineering (NCSOSE) at Old Dominion University. His research focuses on Systems Engineering, System of System of Systems Engineering, Management Cybernetics, and Complex System Governance. He is a Fellow, Past President, and 2015 Sarchet Award recipient from American Society for Engineering Management for his pioneering efforts in the field. His research has spanned defense, security, aerospace, healthcare, $R \& D$, and automotive industries. He holds a B.S. in Engineering from the United States Military Academy (West Point), a M.A. in Management from Central Michigan University, and a Ph.D. in Engineering Management from Old Dominion University. His memberships include the American Society for Engineering Management, the International Council on Systems Engineering, the Institute for Industrial Engineers, and the International Society for System Sciences.

Enrico Zio is the Director of the Chair in Complex Systems and the Energetic Challenge of the European Foundation for New Energy of Électricité de France (EDF) at École Centrale Paris and Supélec and serves a full professor Graduate School in Politecnico di Milano. He holds a BSc in Nuclear Engineering from Politecnico di Milano, Milan, Italy, a MSc in Mechanical Engineering from the University of California, Los Angeles, Los Angeles, California, and $\mathrm{PhD}$ in Nuclear Engineering from Politecnico di Milano, Milan, Italy. He also holds a $\mathrm{PhD}$ in Nuclear Engineering from Massachusetts Institute of Technology Cambridge, Massachusetts. He serves on a number of editorial boards including Reliability Engineering and System Safety, Journal of Risk and Reliability, and International Journal of Computational Intelligence Systems. His research focuses on characterization and modeling of failure/repair/maintenance behavior of components, complex systems and critical infrastructures.
Adrian V. Gheorghe holds a M.Sc. in Electrical Engineering from the Faculty of Power Engineering, Bucharest Polytechnic Institute, Bucharest, Romania, a PhD in Systems Science/Systems Engineering from City University, London, United Kingdom, an MBA from Academy of Economic Studies, Bucharest, Romania, and a M.Sc. Engineering-Economics, Bucharest Polytechnic Institute, Bucharest, Romania. He serves as Senior Scientist with the European Institute for Risk and Communication Management, Bucharest, Romania and Vice President World Security Forum, Langenthal, Switzerland. He is a Professor of Engineering Management and Systems Engineering and is the Batten Endowed Chair on System of Systems Engineering with the Department of Engineering Management and Systems Engineering at Old Dominion University, Norfolk, Virginia. 